\title{
The Essential Role for Laboratory Studies in Atmospheric Chemistry
}

James B. Burkholder*(1)

Earth System Research Laboratory, Chemical Sciences Division, National Oceanic and Atmospheric Administration, Boulder, Colorado 80305, United States

Jonathan P. D. Abbatt*(1)

Department of Chemistry, University of Toronto, Toronto, Ontario, M5S 3H6, Canada

Ian Barnes

University of Wuppertal, School of Mathematics and Natural Science, Institute of Atmospheric and Environmental Research, Gauss Strasse 20, 42119 Wuppertal, Germany

James M. Roberts

Earth System Research Laboratory, Chemical Sciences Division, National Oceanic and Atmospheric Administration, Boulder, Colorado 80305, United States

Megan L. Melamed

IGAC Executive Officer, University of Colorado/CIRES, Boulder, Colorado 80309-0216 United States

Markus Ammann ${ }^{\circledR}$

Laboratory of Environmental Chemistry, Paul Scherrer Institute, Villigen, 5232, Switzerland

Allan K. Bertram

Department of Chemistry, The University of British Columbia, Vancouver, British Columbia, V6T 1Z1, Canada

Christopher D. Cappa

Department of Civil and Environmental Engineering, University of California, Davis, California 95616, United States,

Annmarie G. Carlton

Department of Chemistry, University of California, Irvine, California 92617, United States

Lucy J. Carpenter

Wolfson Atmospheric Chemistry Laboratories, Department of Chemistry, University of York, York, United Kingdom, YO10 5DD,

John N. Crowley

Max Planck Institut für Chemie, Mainz, Germany

Yael Dubowski

Faculty of Civil and Environmental Engineering Technion, Israel Institute of Technology, Haifa 32000, Israel

Published: February 7, 2017 


\section{Christian George ${ }^{(0)}$}

Université Lyon 1CNRS, UMR5256, IRCELYON, Institut de recherches sur la catalyse et l'environnement de Lyon,

Villeurbanne F-69626, France

Dwayne E. Heard

School of Chemistry, University of Leeds, Leeds, LS2 9JT, United Kingdom

\section{Hartmut Herrmann}

Leibniz-Institut für Troposphärenforschung (TROPOS), D-04318 Leipzig, Germany

\section{Frank N. Keutsch}

Department of Chemistry and Chemical Biology, Harvard University, Cambridge, Massachusetts 02128, United States

\section{Jesse H. Kroll}

Department of Civil and Environmental Engineering, Department of Chemical Engineering, Massachusetts Institute of Technology, Cambridge, Massachusetts 02139, United States

\section{Faye McNeill}

Chemical Engineering, Columbia University, New York, New York, United States

\section{Nga Lee Ng}

School of Chemical \& Biomolecular Engineering and School of Earth and Atmospheric Sciences, Georgia Institute of Technology, Atlanta, Georgia, United States

\section{Sergey A. Nizkorodov}

Department of Chemistry University of California, Irvine, California 92697, United States

\section{John J. Orlando}

National Center for Atmospheric Research, Atmospheric Chemistry Observations and Modeling Laboratory, Boulder, Colorado 80301, United States

\section{Carl J. Percival}

School of Earth, Atmospheric and Environmental Sciences, University of Manchester, Manchester, United Kingdom

\section{Bénédicte Picquet-Varrault}

Laboratoire Interuniversitaire des Systèmes Atmosphériques (LISA), UMR 7583 CNRS, Universités Paris-Est Créteil et Paris Diderot, Institut Pierre-Simon Laplace, Créteil Cedex, France

\section{Yinon Rudich}

Department of Earth and Planetary Sciences, Weizmann Institute of Science, Rehovot 76100, Israel

\section{Paul W. Seakins}

School of Chemistry, University of Leeds, Leeds, LS2 9JT, United Kingdom

Jason D. Surratt

Department of Environmental Sciences and Engineering, University of North Carolina at Chapel Hill, Chapel Hill, North Carolina 27599, United States 


\title{
Hiroshi Tanimoto
}

National Institute for Environmental Studies, Tsukuba, Ibaraki Japan

\section{Joel A. Thornton}

Department of Atmospheric Sciences, University of Washington, Seattle, Washington 98195, United States

\section{Zhu Tong \\ College of Environmental Sciences and Engineering, Peking University, Beijing, China}

\section{Geoffrey S. Tyndall}

National Center for Atmospheric Research, Atmospheric Chemistry Observations and Modeling Laboratory, Boulder, Colorado 80301, United States

\section{Andreas Wahner}

Institue of Energy and Climate Research, IEK-8: Troposphere, Forschungszentrum Jülich GmbH, D-52425 Jülich, Germany

\section{Charles J. Weschler}

Environmental \& Occupational Health Sciences Institute, Rutgers University, Piscataway, New Jersey 08854, United States

\author{
Kevin R. Wilson \\ Chemical Sciences Division, Lawrence Berkeley National Laboratory, Berkeley, California, United States
}

\section{Paul J. Ziemann}

Department of Chemistry and Cooperative Institute for Research in Environmental Sciences, University of Colorado, Boulder, Colorado 80309, United States

ABSTRACT: Laboratory studies of atmospheric chemistry characterize the nature of atmospherically relevant processes down to the molecular level, providing fundamental information used to assess how human activities drive environmental phenomena such as climate change, urban air pollution, ecosystem health, indoor air quality, and stratospheric ozone depletion. Laboratory studies have a central role in addressing the incomplete fundamental knowledge of atmospheric chemistry. This article highlights the evolving science needs for this community and emphasizes how our knowledge is far from complete, hindering our ability to predict the future state of our atmosphere and to respond to emerging global environmental change issues. Laboratory studies provide rich opportunities to expand our understanding of the atmosphere via collaborative research with the modeling and field measurement communities, and with neighboring disciplines.

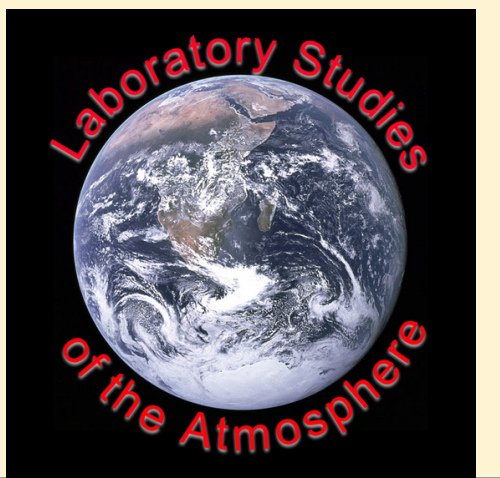

\section{INTRODUCTION}

Atmospheric chemistry is the study of the chemical processes that affect the composition of the atmosphere, encompassing societally important issues such as air pollution and its related health and ecosystem effects, as well as climate (see Figure 1). This field unifies the evaluation of both natural and anthropogenic emissions, measurements of atmospheric composition across a range of temporal and spatial scales, and assessment of deposition processes that ultimately remove chemical compounds from the air. All of these processes are impacted by, or may feedback on, climate change. At the heart of atmospheric chemistry are chemical transformations, often initiated by sunlight. Molecules absorb solar radiation, leading to a cascade of catalytic and oxidative reactions. Our molecular-level understanding of atmospheric chemistry has successfully provided the foundations of air quality forecasts including those related to acid rain, ${ }^{1}$ the basis upon which the chemicals responsible for the formation of the Ozone Hole were banned under the Montreal Protocol and its amendments, ${ }^{2}$ and connections between human impact on atmospheric composition and climate change. ${ }^{3}$ The evaluation of geoengineering as an option to offset global warming also requires a detailed understanding of the underlying chemistry. ${ }^{4}$ 
Simplified parametrizations of this detailed chemistry developed from well-controlled laboratory studies, alongside representations of emissions, transport and deposition processes,

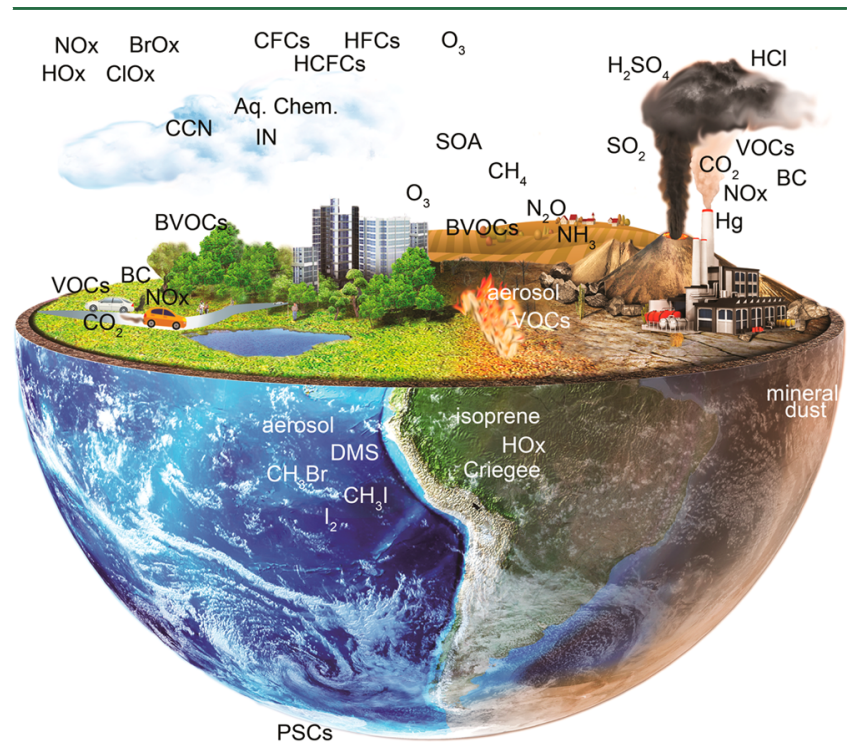

Figure 1. A chemical view of the atmosphere highlighting biogenic and anthropogenic emissions sources and key atmospheric species. are incorporated into computer models to predict atmospheric composition across appropriate temporal and spatial (local, regional, and global) scales. Comparisons with measurements from the field are often used to evaluate model predictions or to help identify poorly represented chemistry. Laboratory studies are an essential bridge between field measurements and models and provide the basic (or fundamental) physics and chemistry of the underlying mechanisms of phenomena observed in the field, which is the basis for generating physically meaningful parametrizations for use in models. This interplay between laboratory studies of chemical, photochemical, and physical processes, atmospheric modeling, and field measurements has propelled the field of atmospheric chemistry forward to achieve remarkable success in understanding the details of stratospheric ozone depletion, acid rain, urban air quality, and the chemistry of climate-forcing agents, and in informing environmental policies (see Figure 2).

The increased emphasis by funding agencies on solutionsdriven research, as opposed to fundamental research of the atmosphere in general, inherently demotivates the development of a comprehensive understanding of the core processes occurring in the atmosphere. In particular, attention and resources are funneled into important but highly specific subfields, such as detailed studies of the atmospheric impacts of different energy source activities including light oil extraction, hydraulic fracturing or bitumen extraction. ${ }^{5}$ Laboratory studies, together

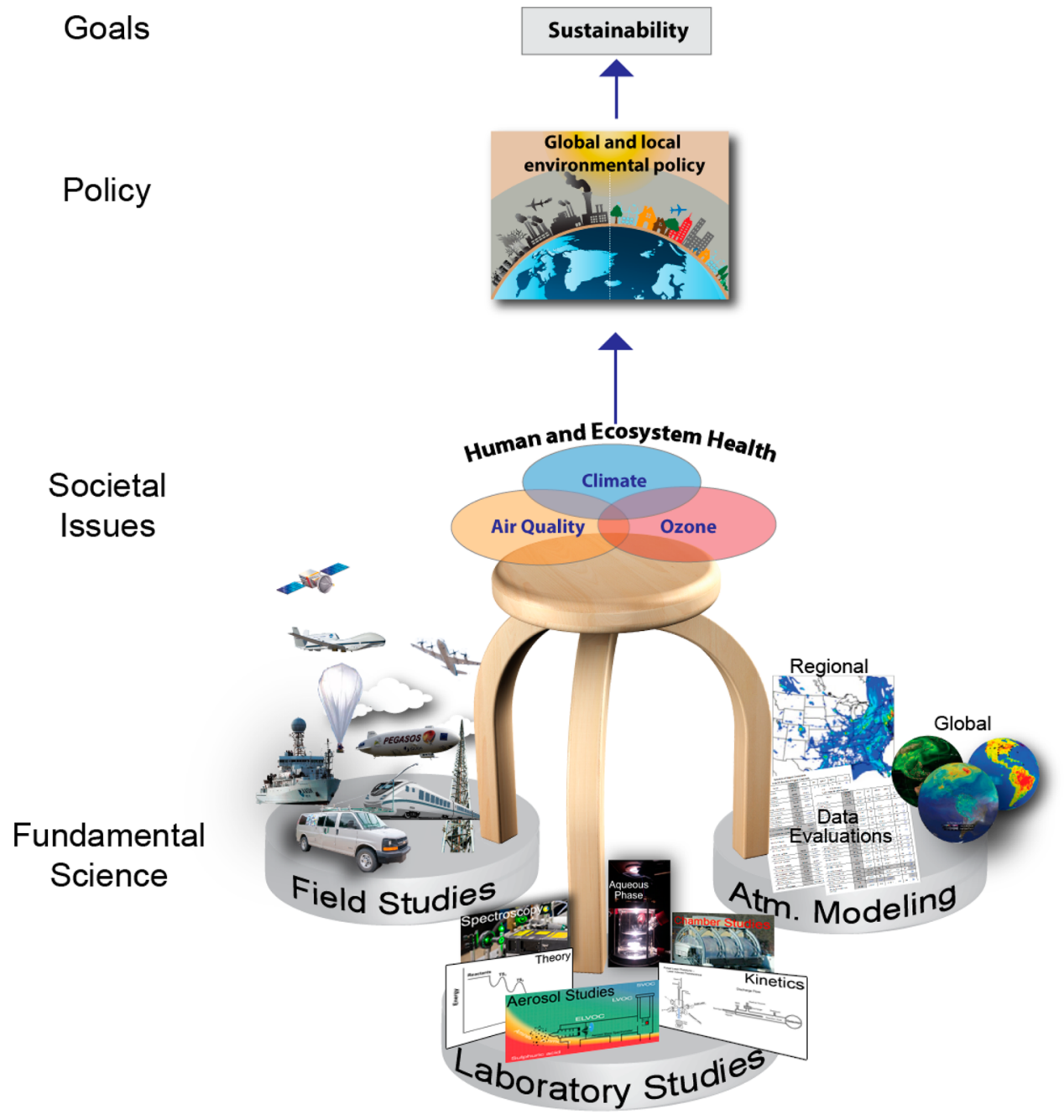

Figure 2. Three-legged stool connecting atmospheric chemistry to sustainable policy. 
A

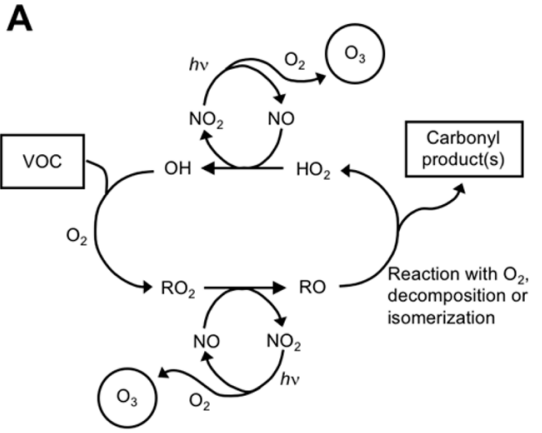

B

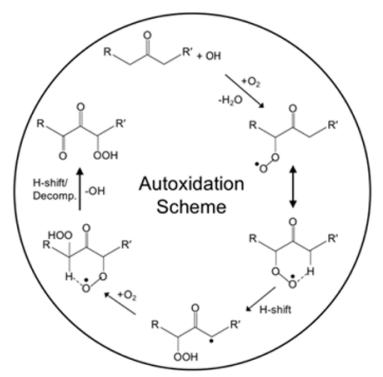

C

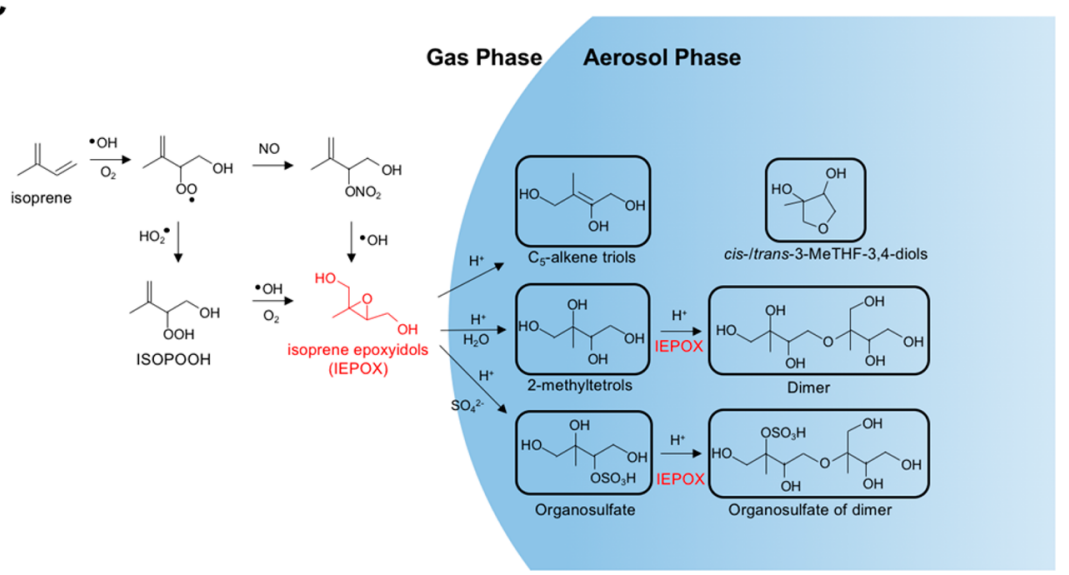

Figure 3. Examples of volatile organic compound (VOC) oxidation mechanisms. A. Formation of ozone coupled to VOC oxidation in the presence of $\mathrm{NO}_{x}$, B. VOC autoxidation scheme adapted from Crounse et al., ${ }^{18} \mathrm{C}$. Isoprene oxidation mechanism emphasizing the interplay between chemistry occurring in both the gas and condensed phases.

with field and modeling studies, constitute the long-standing "three-legged stool" of atmospheric chemistry. The fundamental science aspect of this "three-legged stool" is overshadowed when the science is solutions-driven, lessening our ability to not only address known environmental issues such as the relationship of air quality to human health but also our readiness to respond to unforeseen future environmental threats. Moreover, the complexity of the environment demands avenues both for discovery-based science and for developing and testing hypotheses under well controlled and relevant conditions. Despite the successes mentioned above, the atmosphere is far from being fully understood with regard to changes in composition and the complex interplay of chemical and physical processes, and thus predictive capabilities are limited. The importance of fundamental understanding has been stressed previously, ${ }^{6}$ most recently in the recent report on the Future of Atmospheric Chemistry Research prepared for the National Academy of Science in the United States. ${ }^{7}$

This article highlights the significant role of laboratory-based atmospheric chemistry research, pointing out that our ability to respond to a changing environment and to accurately inform policy development hinges upon a fundamental molecular-level understanding of these processes. Additionally, a commitment from universities, research centers, and governmental agencies to support such research activities in a meaningful way and to promote innovative and interdisciplinary research is needed at this time of a rapidly changing atmospheric composition. Several key challenges and opportunities facing the laboratory community are presented in this article.
A. Emerging Topics for Future Laboratory Studies in Atmospheric Chemistry. The atmospheric chemistry community has traditionally relied on laboratory studies to determine the rates and mechanisms of key gas-phase reactions. For example, these processes have been shown to be important for better understanding ozone depletion in the stratosphere and the coupled processes of tropospheric oxidant production and organic oxidation that control the abundance of key climate forcing agents such as methane $\left(\mathrm{CH}_{4}\right)$ and dimethyl sulfide (DMS) ${ }^{2,8}$ There is currently considerable focus on the chemistry that occurs within or on aerosol particles and cloud droplets, and increasingly on the interface of the atmosphere with the oceans, biosphere, cryosphere, and indoor environments. $^{9-13}$

Recent advances that highlight how far we have come in this field but, more importantly, how much further we have to go to develop sufficiently accurate and predictive models of the atmosphere are presented below. The examples below demonstrate that chemistry is central to our understanding of the field and that we once thought to be understood, such as volatile organic carbon (VOC) oxidation mechanisms, is much more varied and complex than described by current mechanisms and included in models.

A.i. Do We Understand How Organic Molecules Are Oxidized in the Atmosphere? Our conceptual view of organic oxidation mechanisms (see Figure 3), central to our understanding of smog formation, the lifetime of greenhouse gases such as ozone $\left(\mathrm{O}_{3}\right)$ and methane, and the climate effects of aerosol particles, has been transformed in the past few years. An example of such a transformation is illustrated by recent 
studies of the chemistry of key biogenic hydrocarbons, isoprene and the monoterpenes, that are emitted from vegetation. Although isoprene is the largest source of organic carbon to the atmosphere and even a component of exhaled human breath, our understanding of how it is oxidized under appropriate radical concentration conditions is still incomplete. ${ }^{14}$ Only a short time ago, it was not known whether it could contribute to aerosol formation, but recent advances now indicate it is an important aerosol precursor (Figure 3). ${ }^{15,16}$ In particular, when the $\mathrm{OH}$ radical adds to one of isoprene's carbon-carbon double bonds a variety of highly oxidized products form. ${ }^{17}$ The radical intermediates are reactive, and can isomerize leading to efficient autocatalytic oxidation and multifunctionalized compounds that may form aerosol particles. ${ }^{18}$ Similarly, $\alpha$-pinene, a monoterpene, is converted into "highly oxidized molecules (HOMs)" (or "extremely low volatility organic compounds", ELVOCs) under atmospheric conditions on time scales of seconds to minutes, with up to 10 oxygen atoms being introduced onto the terpene backbone. ${ }^{19}$ These are all new findings.

Major uncertainties in the oxidation mechanisms of VOCs, particularly biogenic VOCs, still remain. In particular, there is a need to fully establish how much recycling of the $\mathrm{OH}$ radical occurs from isoprene oxidation under different atmospheric conditions. This is especially true in environments with significant input of molecules from biogenic sources, where the impact of $\mathrm{OH}$ recycling on oxidant levels may be significant. ${ }^{20}$ Also important toward understanding the impacts of VOC oxidation are the roles of epoxides and the HOM compounds in the formation of biogenic secondary organic aerosol (SOA), new particles, ${ }^{21}$ and the potential health effects of particles containing these highly oxidized species. Indeed, the recognition that such organics may play a major role in atmospheric particle nucleation and growth processes nicely illustrates another connection between fundamental physical chemistry processes and atmospheric behavior.

Little is known about the chemistry of these highly oxidized multifunctional reaction products with respect to subsequent gas-phase and condensed-phase reactivity, photochemistry and light-absorbing properties, hygroscopicity, and volatility. Further complexity arises through the addition of nitrogenbased functional groups to the molecule via reactions involving nitrogen oxide radicals, amines, or ammonia. Light-absorbing compounds can result that contribute to the colored particles collectively referred to as brown carbon aerosol and known to arise from burning processes. This has implications for climate change given that biomass burning and wildfire emission sources are expected to increase in the future. ${ }^{22}$

Our framework for understanding the multiphase chemistry of when these oxidized products partition from the gas phase to cloudwater or an aerosol particle is in its infancy. Questions that arise include: How important are radical processes compared to nonradical nucleophilic/electrophilic, hydrolytic, and addition/condensation reactions? ${ }^{23}$ How important are nonideal solution effects and how can they best be treated to help interpret field investigations and improve representations in models $?^{24}$ These issues can be addressed with focused laboratory studies coming out of the coupled atmosphericphysical-analytical chemistry laboratory communities.

A.ii. What Controls the Major Oxidants in the Atmosphere? The chemistry of reactive chemical intermediatesusually radicals-is at the heart of atmospheric chemistry (see Figure 4). Although our understanding of reaction mechanisms initiated by conventional oxidants $\left(\mathrm{OH}, \mathrm{Cl}, \mathrm{O}_{3}\right)$ is extensive,

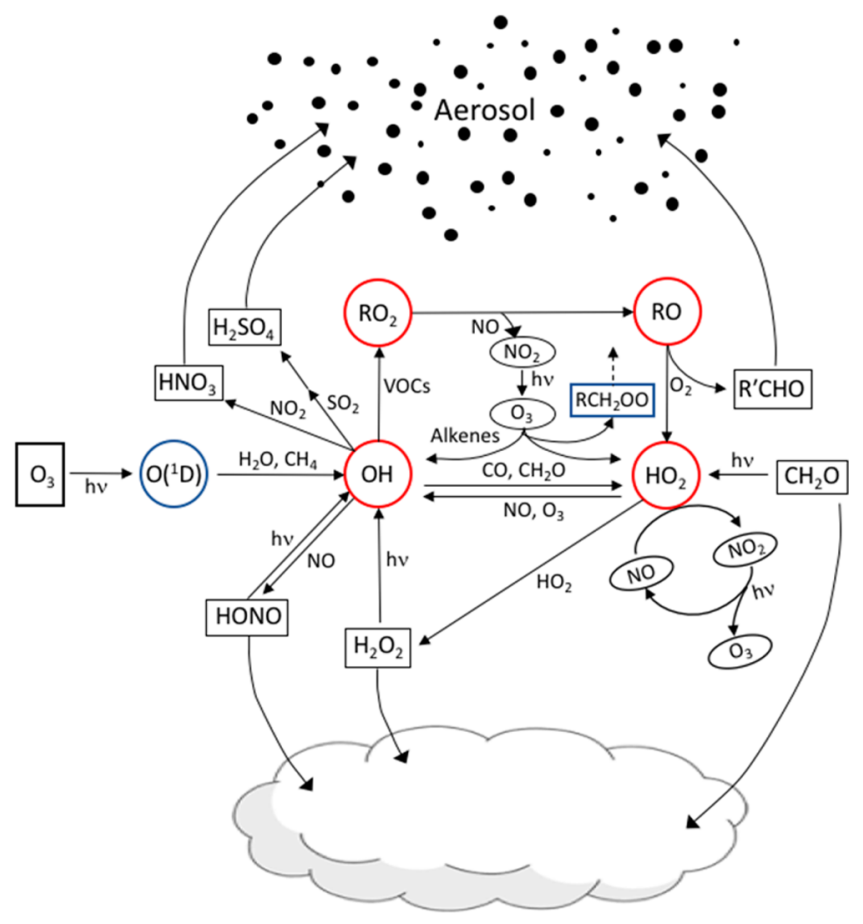

Figure 4. Examples of radical formation, cycling, formation of stable products, and contributions to aerosol and cloud chemistry. Note that radical chemistry also occurs in cloud droplets and aerosol particles but is not shown.

it is not complete and the importance of new classes of reactive intermediates, e.g. Criegee intermediates, is now being recognized and studied. For example, although the rapid cycling of $\mathrm{OH}$ and $\mathrm{HO}_{2}$ radicals helps to drive the chemistry that forms multifunctional organic compounds, the field still does not yet have closure between measured and modeled $\mathrm{OH}$ concentrations in clean environments. ${ }^{20,25}$

Beyond gas-phase $\mathrm{OH}$, there has been a recent surge of activity in the chemistry of other reactive intermediates, notably nitrate radicals, ${ }^{26}$ halogen oxide radicals, Criegee intermediates, and compounds active as photosensitizers, ${ }^{27}$ but our understanding of these processes remains largely insufficient. The Criegee intermediates present a compelling story, having recently been observed for the first time via advanced mass spectrometry techniques. ${ }^{28,29}$ These reactive species are formed when ozone reacts in the gas phase with carbon-carbon double bonds, and their involvement in the oxidation of key molecules, such as $\mathrm{SO}_{2}$, thus affecting new particle formation, is now being studied.

A.iii. What Is the Atmospheric Importance of Multiphase Chemistry? Some of the largest uncertainties in our field arise from the chemistry and photochemistry that takes place involving different interfaces and media, such as aerosol particles and cloud droplets, that interact with gas phase constituents. Collectively, this is referred to as multiphase chemistry (see Figure 5). ${ }^{30}$

The organic aerosol medium represents a poorly characterized component of particle chemistry that can affect partitioning of gas-phase organics and can promote chemistry distinctly different from that which occurs in other chemical environments. Aqueous phase droplets and particles can enhance the formation of organic aerosol by promoting soluble organic partitioning and subsequent reactions. ${ }^{31}$ Constraining advances in the field of organic particle and mixed organic-inorganic 


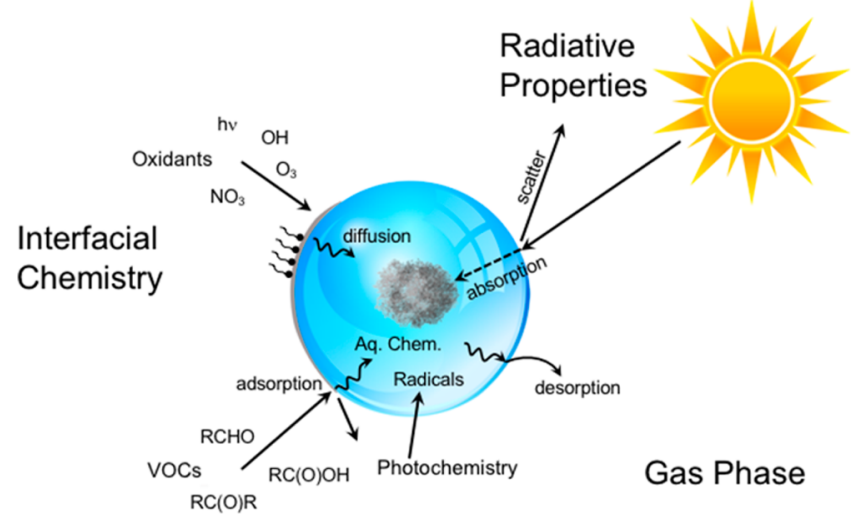

Figure 5. Representation of multiphase processes and radiative properties for a particle or droplet containing a solid core. Note that other particle morphologies are possible.

particle chemistry is our lack of detailed knowledge of the bulk composition, phase state, morphology, transport properties, interfacial composition, and photochemistry within these particles under environmental conditions. ${ }^{27,32}$ The development of new methodologies, such as spectroscopic and mass spectrometric approaches, that are able to better characterize these properties at the individual particle level is a key challenge. In addition, limitations currently exist in our ability to prepare appropriately complex model substances in the laboratory that realistically resemble those present in the environment.

Since particles can indirectly modify climate by acting as cloud condensation nuclei (CCN) and ice nuclei (IN) an important area of multiphase chemistry involves studies of the hygroscopicity of atmospheric particles. ${ }^{33}$ Although much has been learned about the relationship of aerosol particle composition to hygroscopicity and CCN activity, the roles of interfacial processes and organic substituents are still being resolved. $^{34,35}$ Our understanding of the IN activity of aerosol particles is even less refined because we lack a first-principles model that can accurately predict the rates of heterogeneous ice nucleation as a function of aerosol type and composition. ${ }^{36}$

The atmosphere interacts with the surfaces of the oceans, vegetation, soil, and indoor environments. To illustrate such interactions, a long-standing uncertainty in atmospheric chemistry has been related to nongas phase sources of HONO, a photolytic source of the $\mathrm{OH}$ radical. To explain measured levels within many boundary layer environments, it is known that during the day there is a source that forms HONO much faster than the traditional gas-phase formation route. ${ }^{37,38}$ A variety of mechanisms have been proposed, all involving interfacial chemistry. ${ }^{39-42}$

A highly interdisciplinary frontier lies with the impacts of atmospheric particles on human health. Reactive oxygen species (ROS), such as hydrogen peroxide or organic hydroperoxides, are a class of molecules that can give rise to oxidative stress, the state where the human body's oxidant and antioxidant balance is disrupted. ${ }^{43}$ Also important to oxidative stress are molecules with labile oxidation states and metals that promote the formation of ROS species, either in inhaled atmospheric particles or the body. ${ }^{44-46}$ A key question is the degree to which these molecules drive oxidative stress in the body and whether their sources are endogenous or exogenous. Moving ahead in this field requires the collaboration of atmospheric chemists and toxicologists.
B. Challenges and Opportunities in Laboratory Atmospheric Chemistry Research. B.i. Complexity. The atmosphere has many chemical constituents and processes interacting in a nonlinear manner. The complexity that arises in the system has typically been addressed by a reductionist approach where every relevant rate constant and photochemical property is measured. For example, this approach is used to predict the nonlinear response of urban ozone to changing $\mathrm{NO}_{x}$ emissions, a relationship now well-recognized in the air pollution control community and with connections to climate change. ${ }^{8,47}$ But other complex interactions are less well understood. For example, how do chemical interactions with aerosol particles affect the aerosols' ability to nucleate liquid water and ice clouds? How does the liquid-like layer that exists at the surface of snow affect the likelihood of molecules being sorbed from the gas phase? ${ }^{48}$ How does biology affect the indoor microbiome and its ability to change VOC levels? ${ }^{13}$ And, what is the interplay between biology and chemistry in controlling the fluxes of climatically active gases such as DMS and isoprene to the atmosphere from the ocean and vegetation. ${ }^{9,12}$

A reductionist approach is necessary to arrive at the understanding required for confidence in model predictions of air quality and climate. Nevertheless, it is also fruitful to work with top-down methods where observations from laboratory experiments conducted under conditions close to those in the environment can be parametrized for inclusion in models. For example, it is now possible to measure the rate of loss of a gasphase reactant to ambient aerosol under real-world conditions. ${ }^{49}$ The goal of such experiments is to obtain quantitative closure between the bottom-up and top-down approaches for assessing the rates of this chemistry.

B.ii. Collaboration and Interdisciplinary Research. In addition to the value of single-investigator science, atmospheric chemistry has also long benefited from collaboration. A number of schemes can enhance opportunities for collaboration. In particular, there is an advantage to incorporating laboratory projects into the funding of large field campaigns, to facilitate exchange of ideas and experimental techniques from one community to another. Another approach is for a small number of research teams to work together to simultaneously study the chemistry in one facility, to examine the nature of complex processes. ${ }^{50}$ Recent advances in theoretical methods mean that quantum chemical calculations can significantly enhance knowledge gained from laboratory investigations. In addition, collaborations between laboratory scientists and atmospheric modelers are required to enable both direct impact-testing of laboratory data and identify areas of research for which remaining uncertainty has significant repercussions.

New interdisciplinary opportunities are continuing to arise at the interfaces of atmospheric chemistry. For example, dedicated lab experiments under controlled conditions will inform us regarding the nature of biosphere-atmosphere interactions. ${ }^{51}$ This, in turn, will help us to better understand how ecosystem health is affected via atmospheric exposures and will aid in determining the detailed mechanisms by which vegetation removes oxidants from the atmosphere. Another example is the chemistry involving atmospheric constituents and the lung-air interface. Experiments conducted jointly by atmospheric chemists and toxicologists will better establish how airborne particles contribute to increased levels of oxidative stress, a common hypothesis invoked to explain the epidemiological connections between increased particulate loadings and negative health outcomes. ${ }^{52}$ There is also considerable scope 
for new explorations in indoor environments where we spend most of our time and receive most of our pollutant exposure. ${ }^{13}$ Indoor surface-area-to-volume ratios are high, suggestive of the importance of surface chemistry, and many cleaning and personal care products whose constituents partition between the gas phase and indoor surfaces are prevalent. ${ }^{53}$ Furthermore, the desire to reduce energy consumption in some modern buildings may lead to less ventilated indoor environments, and requires better understanding of indoor air chemistry to ensure that such green buildings are also healthy buildings.

For all these opportunities, there is the need for science funding agencies to recognize that such interdisciplinary research often falls between the cracks of funding programs that are better tuned to promote the value of disciplinary research.

B.iii. The Interplay of Laboratory Experiments with Computational and Atmospheric Modeling Scientists. Connecting laboratory experiments to chemical theory remains crucial to the atmospheric chemistry field. At the molecular level, as computational methods allow for increasingly complex chemistry to be studied on a computer, ${ }^{54}$ interactions between laboratory and computational chemists are expected to become more common.

Individual gas-phase rate or photochemical parameters may be easily incorporated into chemical transport models and their impact evaluated. However, the challenge of transferring laboratory results from complex systems is not as straightforward. The evaluation of physical and chemical laboratory data as provided by the NASA JPL (http://jpldataeval.jpl.nasa.gov/) and IUPAC (http://iupac.pole-ether.fr/) panels is a particularly important task that supports feedback between modelers and experimentalists in both directions. ${ }^{55,56}$ Collaborative efforts between laboratory scientists and process-level atmospheric modelers can ensure accurate parametrizations of complex chemistry are incorporated into models, and the integrating nature of the models can provide information about which conditions or time scales need further experimental constraints. Such collaborations can occur as part of research grants, information collaborations, or special sessions at international conferences that emphasize the integration of modeling and laboratory results.

B.iv. The Interplay of Laboratory Experiments with Field Measurements. Many advanced analytical technologies have been developed in the past decade that can be applied to atmospheric chemistry research, with increasingly sensitive and multiplexing instruments deployed in both the lab and atmosphere. In order to understand new field observations the laboratory community is pushed to develop a better understanding of the associated chemistry and its possible environmental impacts. For example, recent progress has arisen from the advent of advanced mass-spectrometric techniques that now allow for the identification and quantification of species present in complex chemical mixtures. ${ }^{57,58}$ Such instrumentation has been used extensively in new studies of particle nucleation and growth processes. ${ }^{21}$ With a strong demand for sensitive and reliable measurement technologies, the atmospheric chemistry field fosters developments in advanced measurement technologies. These advances have led to a recent growth in experimental studies where the relevant chemistry is studied on genuine atmospheric materials (such as atmospheric aerosol particles) commonly referred to as "field-in-the-lab" or "lab-in-the-field" methods. ${ }^{49}$ These approaches are attractive to test the applicability of laboratory model materials and to provide top-down results that fundamental-based bottom-up approaches aspire to match.

\section{CONCLUSIONS}

The scientific uncertainties illustrated above are associated with some of the most central questions in atmospheric chemistry: How are atmospheric molecules transformed, and by what mechanisms? In what phase does this chemistry occur and on what time scale? How does this chemistry affect air quality and climate? How do ecosystems affect atmospheric chemistry and vice versa? How does this chemistry affect the interaction of the atmosphere with other parts of the environment? These issues and others highlight the ongoing central role for laboratory studies and a molecular-level understanding of atmospheric chemistry that enable the development of informed environmental policy.

The laboratory studies community is adapting to address far greater scientific complexity than was apparent only a decade ago, needing to embrace an interdisciplinary and collaborative research approach while at the same time continuing to focus on the measurement of fundamental properties of atmospherically relevant molecules and processes. These aspects of the field are highly attractive to early career scientists who are looking for research experiences outside of traditional disciplines. Funding agencies can facilitate these efforts, by supporting fundamental laboratory science and by promoting interdisciplinary and collaborative research and the interplay between laboratory studies and associated modeling, and field measurement activities.

\section{AUTHOR INFORMATION}

\section{Corresponding Authors}

*E-mail: James.B.Burkholder@noaa.gov.

*E-mail: jabbatt@chem.utoronto.ca.

ORCID

James B. Burkholder: 0000-0001-9532-6246

Jonathan P. D. Abbatt: 0000-0002-3372-334X

Markus Ammann: 0000-0001-5922-9000

Annmarie G. Carlton: 0000-0002-8574-1507

Christian George: 0000-0003-1578-7056

Sergey A. Nizkorodov: 0000-0003-0891-0052

Notes

The authors declare no competing financial interest.

\section{ACKNOWLEDGMENTS}

This article arose from discussions at a workshop sponsored by the International Global Atmospheric Chemistry (IGAC) project (http://www.igacproject.org) on "The Future of Laboratory Studies in Atmospheric Chemistry". As well, we thank NOAA for hosting the event. We thank A. Reiser and D. K. Papanastasiou for help with the figures, and B. Christensen with help during the submission process.

\section{REFERENCES}

(1) U.S. Environmental Protection Agency. https://www.epa.gov/ acidrain.

(2) WMO. Global Ozone Research and Monitoring Project, Report 55; World Meteorological Organization, Scientific Assessment of Ozone Depletion: Geneva, Switzerland, 2014.

(3) IPCC. Climate Change 2013: The Physical Science Basis. Contribution of Working Group 1 to the Fifth Assessment Report of the 
Intergovernmental Panel on Climate Change, Stocker et al., Eds.; Cambridge University Press: Cambridge, UK, 2013.

(4) Vaughan, N. E.; Lenton, T. M. A review of climate geoengineering proposals. Clim. Change 2011, 109, 745-790.

(5) Liggio, J.; Li, S. M.; Hayden, K.; Taha, Y. M.; Stroud, C.; Darlington, A.; Drollette, B. D.; Gordon, M.; Lee, P.; Liu, P.; et al. Oil sands operations as a large source of secondary organic aerosols. Nature 2016, 534, 91-95.

(6) Abbatt, J.; George, C.; Melamed, M.; Monks, P.; Pandis, S.; Rudich, Y. New Directions: Fundamentals of atmospheric chemistry: Keeping a three-legged stool balanced. Atmos. Environ. 2014, 84, 390391.

(7) National Academies of Sciences, Engineering, and Medicine. The Future of Atmospheric Chemistry Research: Remembering Yesterday, Understanding Today, Anticipating Tomorrow; The National Academies Press:Washington, DC, 2016; DOI: 10.17226/235730.

(8) Monks, P. S.; Archibald, A. T.; Colette, A.; Cooper, O.; Coyle, M.; Derwent, R.; Fowler, D.; Granier, C.; Law, K. S.; Mills, G. E.; et al. Tropospheric ozone and its precursors from the urban to the global scale from air quality to short-lived climate forcer. Atmos. Chem. Phys. 2015, 15, 8889-8973.

(9) Carpenter, L. J.; Nightingale, P. D. Chemistry and Release of Gases from the Surface Ocean. Chem. Rev. 2015, 115, 4015-4034.

(10) Abbatt, J. P. D.; Thomas, J. L.; Abrahamsson, K.; Boxe, C.; Granfors, A.; Jones, A. E.; King, M. D.; Saiz-Lopez, A.; Shepson, P. B.; Sodeau, J.; et al. Halogen activation via interactions with environmental ice and snow in the polar lower troposphere and other regions. Atmos. Chem. Phys. 2012, 12, 6237-6271.

(11) McNeill, V. F.; Grannas, A. M.; Abbatt, J. P. D.; Ammann, M.; Ariya, P.; Bartels-Rausch, T.; Domine, F.; Donaldson, D. J.; Guzman, M. I.; Heger, D.; et al. Organics in environmental ices: sources, chemistry, and impacts. Atmos. Chem. Phys. 2012, 12, 9653-9678.

(12) Heald, C. L.; Spracklen, D. V. Land Use Change Impacts on Air Quality and Climate. Chem. Rev. 2015, 115, 4476-4496.

(13) Weschler, C. J. Chemistry in indoor environments: 20 years of research. Indoor Air 2011, 21, 205-218.

(14) Wennberg, P. Let's abandon the high NOx and low NOx terminology. IGAC Newsletter 2013, 50, 3-4.

(15) Surratt, J. D.; Chan, A. W. H.; Eddingsaas, N. C.; Chan, M. N.; Loza, C. L.; Kwan, A. J.; Hersey, S. P.; Flagan, R. C.; Wennberg, P. O.; Seinfeld, J. H. Reactive intermediates revealed in secondary organic aerosol formation from isoprene. Proc. Natl. Acad. Sci. U. S. A. 2010, 107, 6640-6645.

(16) Lin, Y. H.; Zhang, Z. F.; Docherty, K. S.; Zhang, H. F.; Budisulistiorini, S. H.; Rubitschun, C. L.; Shaw, S. L.; Knipping, E. M.; Edgerton, E. S.; Kleindienst, T. E.; et al. Isoprene Epoxydiols as Precursors to Secondary Organic Aerosol Formation: Acid-Catalyzed Reactive Uptake Studies with Authentic Compounds. Environ. Sci. Technol. 2012, 46, 250-258.

(17) Paulot, F.; Crounse, J. D.; Kjaergaard, H. G.; Kurten, A., St; Clair, J. M.; Seinfeld, J. H.; Wennberg, P. O. Unexpected Epoxide Formation in the Gas-Phase Photooxidation of Isoprene. Science 2009, $325,730-733$.

(18) Crounse, J. D.; Nielsen, L. B.; Jorgensen, S.; Kjaergaard, H. G.; Wennberg, P. O. Autoxidation of Organic Compounds in the Atmosphere. J. Phys. Chem. Lett. 2013, 4, 3513-3520.

(19) Ehn, M.; Thornton, J. A.; Kleist, E.; Sipila, M.; Junninen, H.; Pullinen, I.; Springer, M.; Rubach, F.; Tillmann, R.; Lee, B.; et al. A large source of low-volatility secondary organic aerosol. Nature 2014, 506, 476-480.

(20) Stone, D.; Whalley, L. K.; Heard, D. E. Tropospheric OH and $\mathrm{HO}_{2}$ radicals: field measurements and model comparisons. Chem. Soc. Rev. 2012, 41, 6348-6404.

(21) Trostl, J.; Chuang, W. K.; Gordon, H.; Heinritzi, M.; Yan, C.; Molteni, U.; Ahlm, L.; Frege, C.; Bianchi, F.; Wagner, R.; et al. The role of low-volatility organic compounds in initial particle growth in the atmosphere. Nature 2016, 533, 527-530.

(22) Laskin, A.; Laskin, J.; Nizkorodov, S. A. Chemistry of Atmospheric Brown Carbon. Chem. Rev. 2015, 115, 4335-4382.
(23) Jang, M. S.; Czoschke, N. M.; Lee, S.; Kamens, R. M. Heterogeneous atmospheric aerosol production by acid-catalyzed particle-phase reactions. Science 2002, 298, 814-817.

(24) Herrmann, H.; Schaefer, T.; Tilgner, A.; Styler, S. A.; Weller, C.; Teich, M.; Otto, T. Tropospheric Aqueous-Phase Chemistry: Kinetics, Mechanisms, and Its Coupling to a Changing Gas Phase. Chem. Rev. 2015, 115, 4259-4334.

(25) Rohrer, F.; Lu, K. D.; Hofzumahaus, A.; Bohn, B.; Brauers, T.; Chang, C. C.; Fuchs, H.; Haseler, R.; Holland, F.; Hu, M.; et al. Maximum efficiency in the hydroxyl-radical-based self-cleansing of the troposphere. Nat. Geosci. 2014, 7, 559-563.

(26) Ng, N. L.; Brown, S. S.; Archibald, A. T.; Atlas, E.; R.C, C.; Crowley, J. N.; Day, D. A.; Donahue, N. M.; Fry, J. L.; al, F. Nitrate radicals and biogenic volatile organic compounds: Oxidation, mechanisms and organic aerosol. Atmos. Chem. Phys. Discuss. 2016, DOI: $10.5194 /$ acp-2016-734.

(27) George, C.; Ammann, M.; D’Anna, B.; Donaldson, D. J.; Nizkorodov, S. A. Heterogeneous Photochemistry in the Atmosphere. Chem. Rev. 2015, 115, 4218-4258.

(28) Taatjes, C. A.; Shallcross, D. E.; Percival, C. J. Research frontiers in the chemistry of Criegee intermediates and tropospheric ozonolysis. Phys. Chem. Chem. Phys. 2014, 16, 1704-1718.

(29) Welz, O.; Savee, J. D.; Osborn, D. L.; Vasu, S. S.; Percival, C. J.; Shallcross, D. E.; Taatjes, C. A. Direct Kinetic Measurements of Criegee Intermediate $\left(\mathrm{CH}_{2} \mathrm{OO}\right)$ Formed by Reaction of $\mathrm{CH}_{2} \mathrm{I}$ with $\mathrm{O}_{2}$. Science 2012, 335, 204-207.

(30) Poschl, U.; Shiraiwa, M. Multiphase Chemistry at the Atmosphere-Biosphere Interface Influencing Climate and Public Health in the Anthropocene. Chem. Rev. 2015, 115, 4440-4475.

(31) Ervens, B.; Turpin, B. J.; Weber, R. J. Secondary organic aerosol formation in cloud droplets and aqueous particles (aqSOA): a review of laboratory, field and model studies. Atmos. Chem. Phys. 2011, 11, $11069-11102$.

(32) Koop, T.; Bookhold, J.; Shiraiwa, M.; Poschl, U. Glass transition and phase state of organic compounds: dependency on molecular properties and implications for secondary organic aerosols in the atmosphere. Phys. Chem. Chem. Phys. 2011, 13, 19238-19255.

(33) Petters, M. D.; Kreidenweis, S. M. A single parameter representation of hygroscopic growth and cloud condensation nucleus activity. Atmos. Chem. Phys. 2007, 7, 1961-1971.

(34) Ruehl, C. R.; Davies, J. F.; Wilson, K. R. An interfacial mechanism for cloud droplet formation on organic aerosols. Science 2016, 351, 1447-1450.

(35) Noziere, B.; Baduel, C.; Jaffrezo, J. L. The dynamic surface tension of atmospheric aerosol surfactants reveals new aspects of cloud activation. Nat. Commun. 2014, 5, 7-12.

(36) Hoose, C.; Mohler, O. Heterogeneous ice nucleation on atmospheric aerosols: a review of results from laboratory experiments. Atmos. Chem. Phys. 2012, 12, 9817-9854.

(37) Kleffmann, J. Daytime sources of nitrous acid (HONO) in the atmospheric boundary layer. ChemPhysChem 2007, 8, 1137-1144.

(38) Li, X.; Rohrer, F.; Hofzumahaus, A.; Brauers, T.; Haseler, R.; Bohn, B.; Broch, S.; Fuchs, H.; Gomm, S.; Holland, F.; et al. Missing Gas-Phase Source of HONO Inferred from Zeppelin Measurements in the Troposphere. Science 2014, 344, 292-296.

(39) George, C.; Strekowski, R. S.; Kleffmann, J.; Stemmler, K.; Ammann, M. Photoenhanced uptake of gaseous $\mathrm{NO}_{2}$ on solid-organic compounds: a photochemical source of HONO? Faraday Discuss. 2005, 130, 195-210.

(40) Ye, C. X.; Zhou, X. L.; Pu, D.; Stutz, J.; Festa, J.; Spolaor, M.; Tsai, C.; Cantrell, C.; Mauldin, R. L.; Campos, T.; et al. Rapid cycling of reactive nitrogen in the marine boundary layer. Nature 2016, 532, 489-491.

(41) VandenBoer, T. C.; Young, C. J.; Talukdar, R. K.; Markovic, M. Z.; Brown, S. S.; Roberts, J. M.; Murphy, J. G. Nocturnal loss and daytime source of nitrous acid through reactive uptake and displacement. Nat. Geosci. 2015, 8, 55-60. 
(42) Donaldson, M. A.; Bish, D. L.; Raff, J. D. Soil surface acidity plays a determining role in the atmospheric-terrestrial exchange of nitrous acid. Proc. Natl. Acad. Sci. U. S. A. 2014, 111, 18472-18477.

(43) Lushchak, V. I. Free radicals, reactive oxygen species, oxidative stress and its classification. Chem.-Biol. Interact. 2014, 224, 164-175.

(44) Charrier, J. G.; Anastasio, C. On dithiothreitol (DTT) as a measure of oxidative potential for ambient particles: evidence for the importance of soluble transition metals. Atmos. Chem. Phys. 2012, 12, 9321-9333.

(45) Squadrito, G. L.; Cueto, R.; Dellinger, B.; Pryor, W. A. Quinoid redox cycling as a mechanism for sustained free radical generation by inhaled airborne particulate matter. Free Radical Biol. Med. 2001, 31, $1132-1138$.

(46) Shuster-Meiseles, T.; Shafer, M. M.; Heo, J. E.; Pardo-Levin, M.; Antkiewicz, D. S.; Schauer, J. J.; Rudich, A.; Rudich, Y. ROSgenerating/ARE-activating capacity of metals in roadway particulate matter deposited in urban environment. Environ. Res. 2016, 146, 252262.

(47) von Schneidemesser, E.; Monks, P. S.; Allan, J. D.; Bruhwiler, L.; Forster, P.; Fowler, D.; Lauer, A.; Morgan, W. T.; Paasonen, P.; Righi, M.; et al. Chemistry and the Linkages between Air Quality and Climate Change. Chem. Rev. 2015, 115, 3856-3897.

(48) Abbatt, J. P. D. Interactions of atmospheric trace gases with ice surfaces: Adsorption and reaction. Chem. Rev. 2003, 103, 4783-4800.

(49) Bertram, T. H.; Thornton, J. A.; Riedel, T. P.; Middlebrook, A. M.; Bahreini, R.; Bates, T. S.; Quinn, P. K.; Coffman, D. J., Direct observations of $\mathrm{N}_{2} \mathrm{O}_{5}$ reactivity on ambient aerosol particles. Geophys. Res. Lett. 2009, 36.10.1029/2009GL040248

(50) Nguyen, T. B.; Crounse, J. D.; Schwantes, R. H.; Teng, A. P.; Bates, K. H.; Zhang, X., St; Clair, J. M.; Brune, W. H.; Tyndall, G. S.; Keutsch, F. N.; et al. Overview of the Focused Isoprene eXperiment at the California Institute of Technology (FIXCIT): mechanistic chamber studies on the oxidation of biogenic compounds. Atmos. Chem. Phys. 2014, 14, 13531-13549.

(51) Mentel, T. F.; Wildt, J.; Kiendler-Scharr, A.; Kleist, E.; Tillmann, R.; Dal Maso, M.; Fisseha, R.; Hohaus, T.; Spahn, H.; Uerlings, R.; et al. Photochemical production of aerosols from real plant emissions. Atmos. Chem. Phys. 2009, 9, 4387-4406.

(52) West, J. J.; Cohen, A.; Dentener, F.; Brunekreef, B.; Zhu, T.; Armstrong, B.; Bell, M. L.; Brauer, M.; Carmichael, G.; Costa, D. L.; et al. What We Breathe Impacts Our Health: Improving Understanding of the Link between Air Pollution and Health. Environ. Sci. Technol. 2016, 50, 4895-4904.

(53) Morrison, G. Interfacial chemistry in indoor environments. Environ. Sci. Technol. 2008, 42, 3494-3499.

(54) Vereecken, L.; Glowacki, D. R.; Pilling, M. J. Theoretical Chemical Kinetics in Tropospheric Chemistry: Methodologies and Applications. Chem. Rev. 2015, 115, 4063-4114.

(55) Cox, R. A. Evaluation of laboratory kinetics and photochemical data for atmospheric chemistry applications. Chem. Soc. Rev. 2012, 41, 6231-6246.

(56) Ammann, M.; Cox, R. A.; Crowley, J. N.; Jenkin, M. E.; Mellouki, A.; Rossi, M. J.; Troe, J.; Wallington, T. J. Evaluated kinetic and photochemical data for atmospheric chemistry: Volume VI heterogeneous reactions with liquid substrates. Atmos. Chem. Phys. 2013, 13, 8045-8228.

(57) Prather, K. A.; Hatch, C. D.; Grassian, V. H. Analysis of Atmospheric Aerosols. Annu. Rev. Anal. Chem. 2008, 1, 485-514.

(58) Lopez-Hilfiker, F. D.; Mohr, C.; Ehn, M.; Rubach, F.; Kleist, E.; Wildt, J.; Mentel, T. F.; Lutz, A.; Hallquist, M.; Worsnop, D.; et al. A novel method for online analysis of gas and particle composition: description and evaluation of a Filter Inlet for Gases and AEROsols (FIGAERO). Atmos. Meas. Tech. 2014, 7, 983-1001. 